\title{
Fecundity of the Japanese Mitten Crab Eriocheir japonica (de Haan)
}

\author{
Satoshi Kobayashi \\ Laboratory of Functional Marine Biology, Graduate School of Agriculture, Kyoto University, \\ Kitashirakawa Oiwake-chou, Sakyo-ku, Kyoto 606-8502, Japan
}

\begin{abstract}
Fecundity of the Japanese mitten crab Eriocheir japonica was investigated at Tsuyazaki Beach, Fukuoka Prefecture, Japan. The numbers of eggs and hatched larvae counted in the laboratory were combined and categorized by the number of ovipositions. When the number of oviposition could not be directly counted, it was estimated based on the appearance of the egg mass. The fecundity increased with increasing carapace width (CW) and decreased in the later ovipositions. It was estimated to range from 120,000 (40 $\mathrm{mm}$ in $\mathrm{CW})$ to $600,000(70 \mathrm{~mm})$ in the first oviposition, 80,000 to 300,000 in the second one and 20,000 to 80,000 in the third one. Females oviposit up to three times within one reproductive season and die without further moulting. Considering the energetic cost of migration, it may be more profitable to consume all accumulated energy within one reproductive season, and spawn many offspring while they are not exhausted just after migration. Potential lifetime fecundity can be estimated from the total fecundity; it ranged from 230,000 ( $40 \mathrm{~mm}$ in $\mathrm{CW})$ to $980,000(70 \mathrm{~mm})$. When compared to other marine grapsid crabs, maturity size and fecundity of the first oviposition of E. japonica are both larger, but the regression line describing the $\mathrm{CW}$ - fecundity relationship is similar to those of other grapsid crabs. Large fecundity per brood with large maturity size compensates for the decrease in their brooding time and lifetime fecundity.
\end{abstract}

Key words: Eriocheir japonica, times of brood, diadromous migration, lifetime fecundity, lifetime reproductive success, marine grapsid crab

\section{INTRODUCTION}

The Japanese mitten crab Eriocheir japonica (de Haan) is a grapsid crab distributed in Sakhalin, east Korea, Japan and Taiwan (Miyake 1983). This catadromous species is widely distributed from the upper region of rivers to estuarine and coastal areas. It is a large benthic species which is distributed over a wide area, suggesting that it occupies an important ecological niche in rivers and coastal areas. This crab is also an important fishery target in Japanese rivers. Restocking management programs, such as seed production and the

Received July 12, 2000: Accepted February 5, 2001 release of young crabs, are in progress to protect the natural population from overexploitation (Kobayashi et al. 1997). Various ecological information is available for this species (Kobayashi \& Matsuura 1991, 1994, 1995a, 1995b, 1995c, 1995d; Kobayashi 1998, as a review for reproductive ecology, see Kobayashi 1999), but there is nothing known about population size and population dynamics (i.e., fecundity, survival rate, life span, etc.), and ecological information on E. japonica is still limited compared with the information available for cohabiting brachyurans distributed in intertidal and shallow subtidal areas in Japan (e.g., Pillay \& Ono 1978; Kikuchi et al. 1981; Fukui \& Wada 1986; Okamoto \& Kurihara 1987; Fukui 1988). The absence of information on E. japonica is caused by its distribution and migration pattern; this crab is widely distributed at comparatively low densities in the rivers 
and sea coastal areas, so it is difficult to collect a large number of samples representing the structure of a whole population. Among the life history parameters, fecundity is the only parameter which can be determined easily, and we can understand the reproductive characteristics of E. japonica by comparing it with those of other grapsid crabs.

In the present paper, the fecundity of E. japonica is recorded using crabs collected in the sea and reared in the laboratory. Among brachyuran crabs, there has been many reports describing the number of broods in one season, fecundity per brood, total egg weight per brood, etc. (for a review see Hines 1982). However, there are few data on the change of fecundity and lifetime fecundity for these species, because they usually grow after the puberty moult and of ten oviposit several times over several years. However in E. japonica after the spawning migration, adult crabs complete reproduction within one reproductive season without moulting (Kobayashi \& Matsuura 1995b), and the potential total lifetime fecundity can be estimated according to the mature body size. In this paper, I estimate the lifetime fecundity of E. japonica and discuss the reproductive characteristics of this species by comparing them with those of other grapsid crabs.

\section{MATERIALS AND METHODS}

Eriocheir japonica was collected using a hand-held net in the intertidal and shallow subtidal area of Tsuyazaki Beach, Munakata County, Fukuoka Prefecture, Japan $\left(34^{\circ} 46^{\prime} \mathrm{N}, 130^{\circ} 28^{\prime} \mathrm{E}\right)$ from September 1991 to May 1992. The crabs were brought to the Fishery Research Laboratory in Tsuyazaki Town, which is less than $500 \mathrm{~m}$ from the collection site.

The crabs were sexed, and the carapace widths (CW) were measured by vernier calipers to the nearest $0.1 \mathrm{~mm}$. Individuals were marked using letter-notched plastic labels stuck onto the carapace with an adhesive agent. Crabs were reared individually in baskets $(33 \mathrm{~cm}$ $\times 55 \mathrm{~cm} \times 33 \mathrm{~cm}$ ) immersed in $500 \ell$ tanks with an open seawater system until June 1992. Crabs were fed daily with a blended mixture of fish, shrimp, squid, clams, wheat, freshwater green algae, cabbage, spinach and pellet diet for prawns. For non-ovigerous females that did not oviposit within a week, a randomly-selected male was introduced into the female's basket until oviposition occurred. The developmental process of eggs was observed, and just before egg hatching, the ovigerous crabs were transferred from the baskets to smaller aquaria $(15 \mathrm{~cm} \times 25 \mathrm{~cm} \times 15 \mathrm{~cm})$ with an open seawater system. A net was set at the outlet of the aquaria, and larvae gathered in the net were then fixed with $10 \%$ formalin. When ovigerous crabs died before their eggs hatched, their pleopods with the attached eggs were dissected and fixed with $10 \%$ formalin. Afterwards eggs were removed from the pleopods using a soft-hair brush, and the collected egg mass was preserved. The numbers of eggs or larvae were estimated using a same method. The total number was estimated after counting the number in a subsample that measured $1 / 16$ or $1 / 32$ of the volume of each mass, and the average value of 4 samples was used to estimate the total number in each brood.

Data were categorized by the number of ovipositions, but there were two groups with different methods to categorize. When non-ovigerous females were collected early in the reproductive season, and they did not oviposit within a week and until after coupling with males, they were determined to be virgin females. This is because there are many virgin females with immature ovaries in the sea in the early part of the reproductive season, and they repeatedly reject copulation until vitellogenesis is completed, and females with matured ovaries oviposit within 24 hours after copulation (Kobayashi 1999). These crabs always spawn a large quantity of egg mass at the first oviposition. For virgin crabs the numbers of ovipositions were directly counted. When the ovigerous females were collected and the number of ovipositions before collection was unknown, the number was estimated based on the relative volume of the egg mass after Kobayashi \& Matsuura (1995b). The volume of egg masses drastically decreases after repeated ovipositions. In the first brood, egg masses are large and well exposed, and the female's abdomen is markedly bent. In the second brood, only a small proportion of the total egg mass is exposed, and the abdomen is only slightly displaced. In the third brood, the presence of eggs is not externally apparent. This method is applicable similarly for all sized crabs (Kobayashi \& Matsuura 1995b). Least squares linear regression lines were fitted to $\mathrm{CW}$ and fecundity data for each time of oviposition after log transformation of the data.

\section{RESULTS}

During the rearing of crabs, I obtained 17 samples of larvae and 14 of eggs for the first broods (the times of oviposition could not be directly counted in 8 and 6 
samples, respectively), 17 and 16 for the second broods ( 3 and 10) and 4 and 6 for the third broods ( 2 and 3 ). The appearance of each ovigerous crab remained almost constant until the eggs hatched, and there was no significant difference between the number of eggs and larvae in the regression lines fitted the $\mathrm{CW}$ - fecundity relationship for each brood (ANCOVA, all were $P>$ 0.05 ). Thus the numbers of eggs and larvae were combined for each brood number.

Fecundity tended to increase with increasing $\mathrm{CW}$; 120,000 to 600,000 for the first brood in the range of 40 $\mathrm{mm}$ to $70 \mathrm{~mm}$ in CW, 80,000 to 300,000 for the second brood and 20,000 to 80,000 for the third brood. There was a significantly positive regression between fecundity and CW in each group (Fig.1). No significant difference was detected in the slopes of the different regression lines $(P>0.05)$, but the $y$-intercepts differed significantly $(P<0.001$, ANCOVA) (Table 1$)$.

The potential total fecundity within one reproductive season can be estimated from body size using the present data; 230,000 at $40 \mathrm{~mm} \mathrm{CW}, 390,000$ at $50 \mathrm{~mm}$ $\mathrm{CW}, 650,000$ at $60 \mathrm{~mm} \mathrm{CW}$ and 980,000 at $70 \mathrm{~mm} \mathrm{CW}$.
Table 1. Results of analysis of covariance between regression lines of carapace width - fecundity relationships in each group indicating time of ovipsition of Eriocheir japonica.

$$
F \text {-value } \quad P
$$

1st brood vs. 2nd brood

$$
\begin{array}{crl}
\text { slope } & 0.108 & >0.05 \\
Y \text {-intercept } & 83.649 & <0.001
\end{array}
$$

2nd brood vs. 3rd brood

$\begin{array}{crl}\text { slope } & 0.099 & >0.05 \\ Y \text {-intercept } & 89.390 & <0.001\end{array}$

1st brood vs. 3rd brood

$\begin{array}{crl}\text { slope } & 0.047 & >0.05 \\ Y \text {-intercept } & 395.481 & <0.001\end{array}$

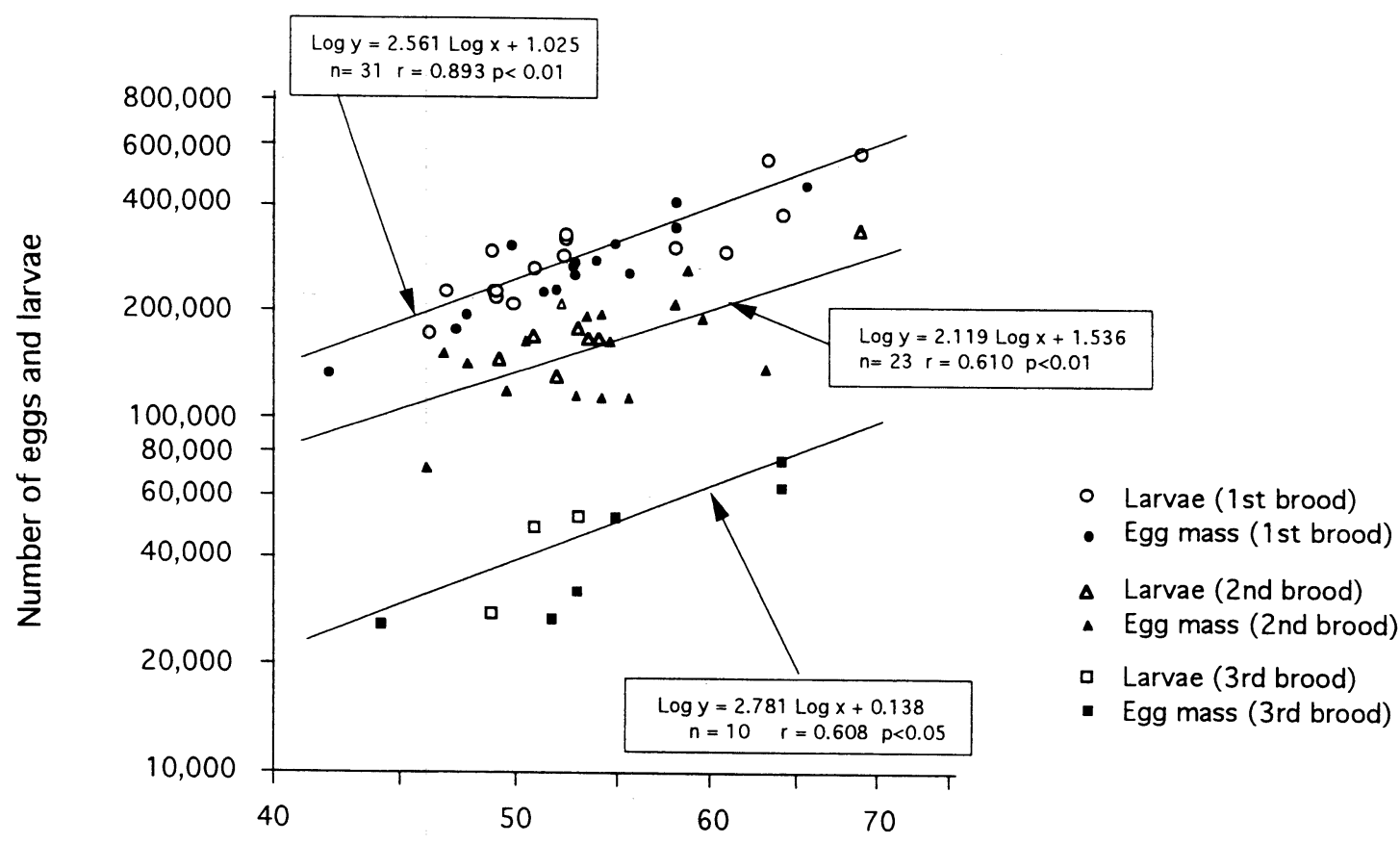

Carapace width $(\mathrm{mm})$

Fig. 1. Regression lines for the number of eggs or larvae per brood relative to carapace width in each time of oviposition of Eriocheir japonica. Axes are natural logarithms. 


\section{DISCUSSION}

Female mitten crabs develop into the adult stage after a puberty moult in the freshwater area of rivers, and migrate to tidal areas over a 3-4 month period as their ovaries develop. Adult crabs start their downstream migration at various stages of ovary maturation. Consequently adult females of various degrees of maturity are collected in the tidal area, and some immature crabs reach the tidal area and spend some time in a nonovigerous condition in this area. Successful copulation occurs only when the ovary is mature, and oviposition occurs just after copulation. After larvae of the first brood hatch, the ovaries restart development and oviposit again after reaching maturity (Kobayashi \& Matsuura 1995a, 1995b; Kobayashi 1999). However, as the number of ovipositions increases, the fecundity of each brood rapidly decreases, as indicated in the present data. Although adult crabs of E. japonica consume a large quantity of food every day, they do not moult and grow while in the marine phase. Probably they rapidly consume metabolic reserves, which were accumulated during the freshwater phase, for reproductive output, but not for growth. Crabs die after one reproductive season. The number of injured crabs (loss of walking legs by autotomy) increases in the later part of the reproductive season, because regeneration of legs only occurs after moulting, which never occurs in the marine phase (Kobayashi \& Matsuura 1997). Exhausted crabs and a large number of dead crabs are also found along the sea coast in the later part of reproductive season. Within its marine phase, individuals can oviposit up to three times and live up to five months (Kobayashi \& Matsuura 1995a), but not all crabs are able to complete three broods, and dead ovigerous crabs are of ten found (Kobayashi unpublished data). Marine grapsid crabs repeatedly moult after the puberty moult and oviposit many times. For example, Hemigrapsus sanguineus (de Haan), H. penicillatus (de Haan) and Gaetice depressus de Haan are estimated to oviposit 5-6 times a year for a total of more than ten times during their lifetime of 2-3 years (Fukui 1988). The characteristic of completing oviposition within one reproductive season as in $E$. japonica is peculiar among grapsid crabs and may be related to the catadromous migration. This crab migrates upstream in freshwater areas for a long distance during its growth period and then disperses into a wide area of the river. Downstream migration for reproduction to the tidal area also requires locomotion over long distances. Consequently crabs that have migrated downstream into the sea will need a high energy level to migrate back to the freshwater area both for enduring the drastic change of osmotic pressure and locomotion in dispersion for a long distance against the flow. In addition, along the southwest coast of Japan (temperate zone), the reproductive season of E. japonica is different from those of other cohabiting brachyura. E. japonica occurs in the sea mainly in late autumn to early spring when other competitive large crabs (e.g., Charybdis japonica) are rare and small grapsid crabs (e.g., Hemigrapsus sanguineus, H. penicillatus and Gaetice depressus) do not participate in reproduction (Kobayashi \& Matsuura 1994). Predators are also comparatively rare in this period. If $E$. japonica remained at the sea coast after reproducing until the next reproductive season, increased competition and predation in summer may affect the survival rate of crabs, which spent much energy for reproduction. Thus it is profitable for E. japonica to complete reproduction and invest all accumulated energy into a large reproductive effort within one season just after completing the downstream migration. Similar reproductive characteristics are also observed in many diadromous (catadromous, anadromous and amphidromous) fishes. They of ten complete their life cycle just after reproduction following the spawning migration (e.g., salmonids, Miyadi et al. 1976). The high migration cost between areas with different osmotic pressure and over long distances may cause this life history pattern.

A decline of fecundity after repeated oviposition has been reported in several animals that have only one reproductive season per lifetime (Begon \& Parker 1986, Ito 1997). Decline of egg size is also observed in these animals, and is thought to be caused by a depletion of energy accumulated for reproduction (Qian \& Chia 1992). As for E. japonica, egg size varies within the long reproductive season, however, this may be due solely to environmental factors and not to the depletion of energy accumulated for reproduction. Egg size of $E$. japonica does not depend on the time of brood and changes merely according to the water temperature; large eggs are spawned and developed at low water temperature and small eggs at high water temperature (Kobayashi \& Matsuura 1995a). In E. japonica, depletion of energy accumulated for reproduction appears in the drastic decrease of fecundity. The first brood accounted for more than $50 \%$ of the total fecundity. This can be explained by the maternal investment strategy related to the maternal condition. It is profitable for female $E$. japonica to spawn many offspring early before they become exhausted (Begon \& Parker 1986). 
Fecundity in the first brood in relation to the carapace width of E. japonica is compared with the data of other cohabiting marine grapsid crabs after Fukui (Fig. 2). The regression line of E. japonica is nearly on the extending lines of those of other species. However, the adult size of E. japonica is $35-75 \mathrm{~mm}$ in $\mathrm{CW}$, which is larger than for other species (Kobayashi \& Matsuura $1995 \mathrm{~b}$ ), and its fecundity is 10-100 times larger than that of other species in the first broods. In general, the reproductive strategy of producing relatively few, large yolk-rich eggs and having an abbreviated larval development is seen as an adaptation to freshwater environments in many different taxa. These reproductive traits have been explained as a significant adaptation to oligotrophic and unstable environments compared with sea areas (Shokita 1979; Mashiko 1990; Anger 1995; Diesel et al. 2000). Figure 2 suggests that the reproductive strategy of E. japonica is of the type characterized by the production of a large number of small eggs and the dispersion of planktonic larvae into the sea, which is the strategy observed in other cohabiting marine grapsid crabs. E. japonica has two separate life phases: a marine phase for reproduction and dispersion, and a freshwater phase for growth (Kobayashi 1999). In the freshwater phase during the postlarval period from the juvenile stage just after settlement until the matured stage, they grow in rivers where direct competition for resources with closely related species seems to be rare (Sato 1978; Kobayashi 2000). E. japonica dominantly occupies its ecological niche in the river community, and this may have permitted the evolution of growth to a large size in the freshwater area. The distribution of the larger maturity size in the upper regions of rivers may support this hypothesis (Kobayashi \& Matsuura 1995c). Larger body size of adult crabs compared to other marine grapsid species can increase the fecundity per brood and compensate for the decrease in the number of broods produced in the life cycle. The separated freshwater phase during the growth period may restrict the length of the reproductive period and the number of broods, but may allow this species to grow larger than other marine grapsid species and thus increase its fecundity per brood.

Because E. japonica completes reproduction in one reproductive season without moulting (Kobayashi \& Matsuura 1995b), we can estimate the potential lifetime fecundity by the total fecundity for 3 broods according to their mature body size. The present results indicated that there was a wide range in the lifetime fecundity. The difference of lifetime fecundity with body size directly corresponds to the difference of lifetime

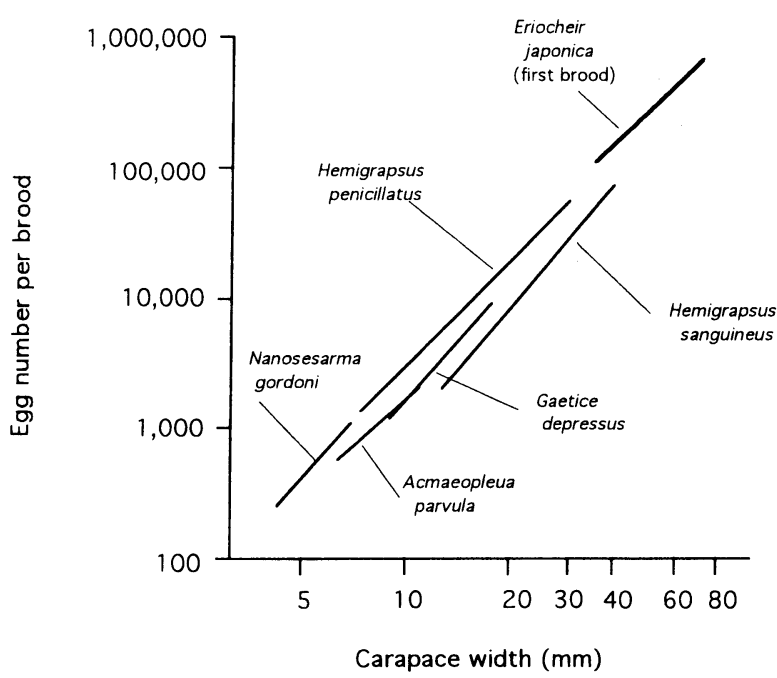

Fig. 2. Regression lines fitted in carapace width - fecundity relationship of Eriocheir japonica in comparison with other marine grapsid crabs. The line of E. japonica is that of the first brood and those of other species are after Fukui (1988). Axes are natural logarithms.

reproductive success. The recorded minimum and maximum sizes of adult female $E$. japonica are $37.5 \mathrm{~mm}$ and $74.8 \mathrm{~mm}$ in $\mathrm{CW}$ in the Kaminokawa River, Kagoshima Prefecture, and $38.0 \mathrm{~mm}$ and $68.4 \mathrm{~mm}$ in $\mathrm{CW}$ at Tsuyazaki Beach (Kobayashi \& Matsuura 1991, 1995b), suggesting that the lifetime fecundity of the maximum sized crabs is nearly 4-5 times as large as that of the minimum sized ones. In other marine grapsid crabs which repeatedly moult after the puberty moult and repeatedly oviposit, the first maturity size is not necessarily related to the lifetime reproductive success. The longevity or number of broods may be important factors in these crabs. Even if the first maturity size is small with low fecundity, they can increase their clutch size and compensate for the total fecundity according to the moulting growth rate. However, predatory pressure on small crabs may be higher, and the duration of their reproductive period may vary with the possibility of predation. Thus their total lifetime fecundity and reproductive success are of ten accidentally determined by the timing of predation. Eriocheir japonica grows and attains maturity in the freshwater areas of rivers, and the maturity size increases in crabs distributed in the upper regions; in the Kaminokawa River, more than $90 \%$ of male crabs collected by traps were $\mathrm{CW}<55 \mathrm{~mm}$ in the lower region, and more than $60 \%$ of them were 55 $\mathrm{mm} \leqq \mathrm{CW}$ in the upper region (Kobayashi \& Matsuura 1995d). Therefore, the lifetime reproductive success of 
female crabs is determined from the habitat within the freshwater area during their growth period. However, the detailed mechanism of increasing maturity size is still unknown. It is not clear if the maturity size is genetically determined or if this trait is determined by the influence of environmental conditions (i.e., temperature or population density). Such a wide variation of lifetime reproductive success may be maintained by the existence of a trade-off between energy cost or mortality during the growth period in freshwater and reproductive success in the marine phase, because the longer time and high energy cost may be necessary for growth to a larger size (Kobayashi \& Matsuura 1995c).

Acknowledgments. I thank the staff of the Laboratory of Marine Biology and the Fisheries Research Laboratory, Faculty of Agriculture, Kyushu University, for their kind assistance. I wish also thank Dr. C. P. Norman, University of Tsukuba, for comments on the manuscript.

\section{REFERENCES}

Anger, K. 1995. The conquest of freshwater and land by marine crabs: adaptations in life-history patterns and larval bioenergetics. Journal of Experimental Marine Biology and Ecology, 193: 119-145.

Begon, M. and G. A. Parker 1986. Should egg size and clutch size decrease with age? Oikos, 47: 293-302.

Diesel, R., C. D. Shubart, and M. Schuh 2000. A reconstruction of the invasion of land by Jamaican crabs (Grapsidae: Sesarminae). Journal of Zoology, London, 250: 141-160.

Fukui, Y. and K. Wada 1986. Distribution and reproduction of four intertidal crabs (Crustacea, Brachyura) in the Tonda River Estuary, Japan. Marine Ecology Progress Series, 30: 229-241.

Fukui, Y. 1988. Comparative studies on the life history of the grapsid crabs (Crustacea, Brachyura) inhabiting intertidal cobble and boulder shores. Publications of the Seto Marine Biological Laboratory, 33: 121-162.

Hines, A. H. 1982. Allometric constraints and variables of reproductive effort in brachyuran crabs. Marine Biology, 69: 309-320.

Ito, K. 1997. Egg-size and -number variations related to maternal size and age, and the relationship between agg size and larval characteristics in an annual marine gastropod, Haloa japonica (Opisthobranchia; Cephalaspidea). Marine Ecology Progress Series, 152:
187-195.

Kikuchi, T., M. Tanaka, S. Nojima and T. Takahashi 1981. Ecological studies on the pebble crab, Gaetice depressus (de Haan). I. Ecological distribution of the crab and environmental conditions. Publication of Amakusa Marine Biological Laboratory, 6: 23-24.

Kobayashi, S. 1998. Settlement and upstream migration of the Japanese mitten crab Eriocheir japonica (de Haan). Ecology and Civil Engineering, 1: 21-31.

Kobayashi, S. 1999. Reproductive ecology of the Japanese mitten crab Eriocheir japonica (de Haan): a review. Japanese Journal of Benthology, 54: 24-35 (in Japanese with English summary).

Kobayashi, S. 2000. Distribution pattern and ecology of brachyuran crabs in the riverine environment: their significance in the ecosystem and present condition. Ecology and Civil Engineering, 3: 113-130 (in Japanese with English summary).

Kobayashi, S. and S. Matsuura 1991. Longitudinal distribution of the Japanese mitten crab in the Kaminokawa River, Kagoshima. Japanese Journal of Scientific Fisheries, 57: 1029-1034 (in Japanese with English summary).

Kobayashi, S. and S. Matsuura 1994. Occurrence pattern and behavior of the Japanese mitten crab Eriocheir japonicus De Haan in the marine environment. Benthos Research, 46: 49-58.

Kobayashi, S. and S. Matsuura 1995a. Egg development and variation of egg size in Japanese mitten crab Eriocheir japonicus (De Haan) in its marine phase. Benthos Research, 48: 29-39.

Kobayashi, S. and S. Matsuura 1995b. Reproductive ecology of the Japanese mitten crab Eriocheir japonicus (De Haan) in its marine phase. Benthos Research, 49:15-28.

Kobayashi, S. and S. Matsuura 1995c. Maturation and oviposition in the Japanese mitten crab Eriocheir japonicus (De Haan) in relation to their downstream migration. Fisheries Science, 61: 766-775.

Kobayashi, S. and S. Matsuura 1995d. Population structure of the Japanese mitten crab Eriocheir japonicus (De Haan) - clinal variations in size of maturity. Crustacean Research, 24: 128-136.

Kobayashi, S. and S. Matsuura 1997. Incidence of limb loss and bald chelipeds in the Japanese mitten crab Eriocheir japonica (De Haan) in its marine phase. Benthos Research, 52: 61-68.

Kobayashi, S., M. Kagehira, T. Yoneji and S. Matsuura 1997. Questionnaire research on the ecology and fishery of the Japanese mitten crab Eriocheir japonica (de Haan). Scientific Bulletin of Faculty of Agriculture, 
Kyushu University, 52: 89-104 (in Japanese with English summary).

Mashiko, K. 1990. Diversified egg and cluch sizes among local populations of the fresh-water prawn Macrobrachyium nipponense (de Haan). Journal of Crustacean Biology, 10: 306-314.

Miyadi, D., H. Kawanabe and N. Mizuno 1976. Colored Ilulustrations of the Freshwater Fishes of Japan. Hoikusha, Tokyo, pp.76-99 (in Japanese).

Miyake, S. 1983. Japanese Crustacean Decapods and Stomatopods in Color, Vol.II, Brachyura (Crabs). Hoikusha, Tokyo, p.174.

Okamoto, K. and Y. Kurihara 1987. Seasonal variation of population structure of Hemigrapsus penicillatus (de Haan) (Crustacea: Brachyura). Japanese Journal of Ecology, 37: 81-89 (in Japanese with English summary).
Pillay, K. K. and Y. Ono 1978. The breeding cycles of two species of grapsid crabs (Crustacea: Decapoda) from the north coast of Kyushu, Japan. Marine Biology, 45: 237-248.

Qian, P-Y. and F-S. Chia 1992. Effect of aging on reproduction in marine polychaete Capitella sp. Journal of Experimental Marine Biology and Ecology, 156: 23-38.

Sato, M. 1978. The distribution of crabs along the streams in Miyajima Island, southwestern Japan, especially on the ecological distribution of Geothelphusa dehaani. Biological Bulletin of Hiroshima University, 44: 2-6 (in Japanese with English summary).

Shokita, S. 1979. The distribution and speciation of the inland water shrimps and prawns from the Ryukyu Islands - II. Bulletin of the College of Science, University of the Ryukyus, 28: 193-278. 